\title{
HANDLING CULTURE
}

\author{
Pieter J.M. van Nispen tot Pannerden \\ ${ }^{a}$ Rotterdam University of Applied Sciences, the Netherlands, \\ e-mail: p.j.m.van.nispen.tot.pannerden@hr.nl
}

\begin{abstract}
Purpose - The article indicates how companies may prepare for and deal with cultural differences. Because the research base is still rather limited an overall perspective may not be realised.

Approach - After discussing definitions and concepts of culture, as well as values, cultural differences between states are discussed, illustrated by a practical example how to prepare for these differences. The focus on states may be explained from the recognition that states still are the source of political, economic and legal frameworks and hence, also the framework for doing business.

Originality - The idea of a cultural competence has hardly been developed but at the same time both business and the multicultural society are asking for it. This cultural competence is an integral combination of knowledge, skills and attitudes for dealing with cultural differences between people.

Implications - Globalising business needs to develop the cultural competence of its managers. Within the EU this applies to nearly all production facilities and quite a few service providers.

Further research - Business needs practical approaches between simple sets of rules for behaviour and scientific approach.
\end{abstract}

Key words: culture; cultural differences; national cultures; cultural competence; values; intercultural communication

Paper type: Conceptual paper

\section{Introduction}

Most people have an idea about culture, whether in terms of the arts or the behaviour of people. However, many of these perceptions are hard to conciliate and may even exclude or contradict one another. This situation makes it hard to find common ground for a study on culture, leave alone that that common ground may function as a starting point for dealing with culture (preventing negative consequences of differences and enhancing co-operation.

Culture is also becoming more important because people are getting more and more involved with one another across borders. In economic terms our societies are globalising rather rapidly, although the crises of the last few years may slow things down. A few economic examples may demonstrate the overall trend. Between 1948 and 2000 the world production of goods increased seven times and world trade in goods 20 times (Hulleman and Marijs, 2003: 62). The export quotient (value of trade divided by gross domestic product) of the world economy increased in the same period from $8 \%$ to $30 \%$, indicating an increase in 
Pieter J.M. van Nispen tot Pannerden

\section{Questions}

Increasing co-operation across borders implies dealing with people with a different background, starting with nationality but more often than not including different patterns of thinking, acting and feeling, or culture (more on definitions below). The question then is how you may deal with cultural differences. In line with the educational approach in the Netherlands we will phrase this question in terms of a cultural competence (Nispen 2011). This approach happens to coincide with that of Thoman and Inkson (2004).

In general terms a competence is an integral combination of knowledge, skills and attitudes. Each job may be described in approximately 10 competences. The 
cultural competence encompasses then knowledge on culture, the skills required to deal with cultural differences and the necessary attitude(s). Skills in this context consist mostly of behaviour and in particular the adaptation of your own behaviour to a different environment. Attitudes include especially respect by reserving your judgement until you have a more comprehensive understanding of the situation. Thomas and Inkson (2004) talk about knowledge, behaviour and mindfulness. Behaviour may be regarded as a major element of skills and mindfulness in turn of attitudes.

The cultural competence needs to be developed over time and through study and experience. Skills and respect need to be exercised in practice. However, knowledge also requires experience. Time and again knowledge on culture remains abstract and relative meaningless if it is not matched with lessons in real life. Although you can never obtain the cultural competence once and for all, the better your understanding of culture, the easier you learn to adapt and to be open to others.

The question now becomes how to obtain this cultural competence. This article focuses on the knowledge part. Skills and attitudes may be mentioned but need to be learned and developed in practice. In order to acquire knowledge on culture this paper aims at answering the following questions:

- what is culture in terms of definitions and concepts?

- what is the position and the effect of values?

- how can we get an idea of the cultural differences between states?

- what is the relation between culture and communication?

- how can we prepare for cultural differences (on the basis of an example from teaching)?

\section{Definitions and Concepts}

Defining culture may be possible but not in a conclusive way as hundreds of definitions and discussions prove. From a sociological perspective culture may be considered as an institution, a way of feeling, thinking and acting of a group of people. Hence, each group from a family up to a state has its own culture. Groups may very specific, like a group of colleagues or a family, or rather less tangible groups, such as all women in the Netherlands or all people who do their shopping in a specific supermarket on Saturday morning. Because each individual is a member of dozens, if not hundreds of groups, each of us is a unique combination of cultures, an individual culture (Figure 1, Hoffman 1999: 191).

The pattern of thinking and acting belonging to each group may be considered as a paradigm and hence, an individual is shifting between paradigms all day long, depending on the groups s/he is in. For that reason Barker (1996: 25) calls culture a paradigm jungle. Each time a person finds himself or herself in a new situation, $\mathrm{s} /$ he tries out whether earlier learned behaviour fits and if not, tries to learn a new
HANDLING CULTURE

Pieter J.M. van Nispen tot Pannerden 
HANDLING

CULTURE

Pieter J.M. van Nispen tot Pannerden

Figure 1.

Individual culture one. This is why dealing with cultural differences requires self-knowledge. In addition you also need to consider that culture is dynamic and hence, research on one day may not be valid the next.

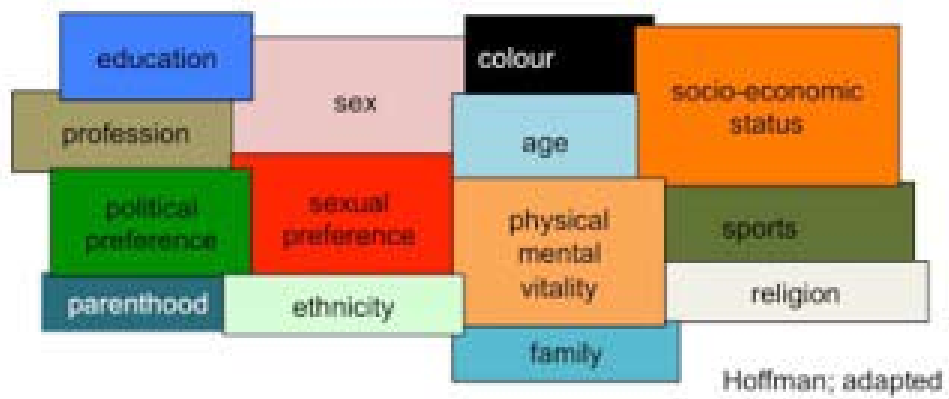

Looking at hundreds of definitions we see that they depend on the discipline of the researcher (in particular cultural anthropology, sociology, psychology and business studies) and the objectives of the research. An overview of the literature goes well beyond the scope of this article and one may even wonder whether it is possible. Reading cultural anthropology in the USA coincides to quite some degree with the study of non-Western sociology in the Netherlands, although the former also includes the Western world. In the Netherlands amongst others cultural sociologists cover that Western part. In addition we see different schools of thought within psychology, such as cross-cultural psychology (studying the behaviour of the individual in relation to the cultural environment, e.g. Oudenhoven 2002), social psychology (focusing on the interaction between individual and group, e.g. Smith and Bond 1998) or with a focus on development (e.g. Valsiner 2000).

The research of culture may also be found in business studies. The focus is less of a scientific and more of an applied nature. Basically, business prefers a model which compares cultures of states in such a way that the results indicates how to handle the differences

Looking at all those definitions and efforts to get a grip on culture, six elements stand out: values and beliefs, thinking and feeling, behaviour, group, time and environment (Figure 2). Theoretically one may combine them in a 'definition' like 'culture is the behaviour of a group of people, based on patterns of thinking and feeling as defined by values and beliefs, at a certain time and place'. However, this is such a wide definition that it becomes useless in practical terms. The UNESCO uses the following definition: culture... is ... the whole complex of distinctive spiritual, material, intellectual and emotional features that characterize a society or social group. It includes not only arts and letters, but also modes of life, the fundamental rights of the human being, value systems, traditions and beliefs (retrieved from its website). 


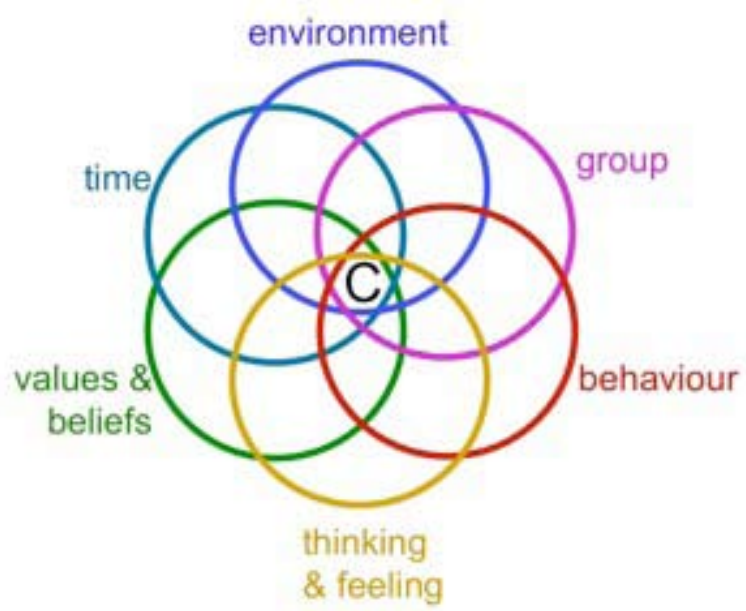

Another approach in getting to grips with culture is drafting concepts or developing models. One example is the model of a reversed triangle (Figure 3), originally developed as a summary of literature. Afterwards it proved its value in teaching and in dealing with cultural differences. The idea behind it is a differentiation in cultures according to the size of groups from large to small. The drawing represents four levels of culture, from top to bottom the levels of the state, the organisation, the small group (team, family) and the individual. By distinguishing between these four levels you may be more specific and more consistent on what you are discussing and hence, avoid confusion. In this way a proper understanding of culture may be obtained.

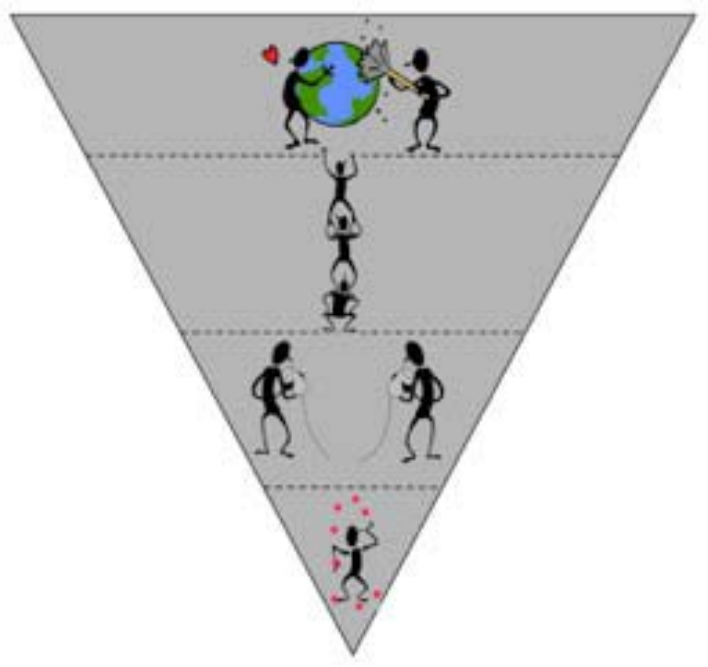

HANDLING

CULTURE

Pieter J.M. van Nispen tot Pannerden

Figure 2. Elements of culture
Figure 3.

Model of a reversed triangle

- 63 
HANDLING

CULTURE

Pieter J.M. van Nispen tot Pannerden
At the bottom individual culture is depicted (the unique combination of memberships of groups and the focus of many psychological studies mentioned above). Important is to note that some balls are on the ground. These represent the social mistakes we make by showing inappropriate behaviour. As a child we would be punished, as an adult we may get a remark in our personnel evaluation or miss out with the distribution of bonuses.

One level up you see the small group, e.g. a family or a project team (see for instance Georgas 2006 or the literature on multicultural teams). At this level interactions with others and communication are added. The individual meets others and has to clarify his/her position, defend his/her interests, ask something et cetera. However, the individual is still recognised as such, an individual person with all his/her good and bad habits and other characteristics.

The second layer of the triangle from above represents the cultures of larger groups, in particular organisational culture (a separate discussion). The picture shows three people standing on top of one another, representing hierarchy. However horizontal or egalitarian an organisation may be, someone is ultimately responsible, implying that no organisation goes without hierarchy. The important thing at this level however, is not hierarchy but that persons do not count on this level that much as individual persons but rather as people who fulfil certain functions in reaching the objectives of the organisation. People at this level are important for their role, not who they are.

Finally, at the top we see culture on the national level (see also below) or the state with patriotism and the like. People are not recognised as individuals but rather as numbers in a population. As a whole they represent that state, they form the political, economic, cultural and other power factors of the state in the international arena.

A state in turn consists of many different organisations, small groups and individuals. The triangle clearly clarifies that culture at the national level is an aggregated concept; an average, which gives an overall idea but which also does not do justice to individual persons. 'I am not my national culture; I only contribute to it'.

The four layers of culture as described above, do not only differ from one another but they also show similarities. At each level two similar processes may be perceived, even if they differ from one another in their expression. These two similarities are answers to the search of individuals and groups for identity and certainty.

\section{Values}

The core of culture consists of values and beliefs. They shape the deepest and strongest motivations of people. Examples of values are justice, individual freedom and thrift. Norms, values and beliefs of groups only change over years, particularly because they are only developed in our pre-adult years of individuals. 
A general definition of values may be found in the European Values Study: "Values are deeply rooted dispositions, orientations, or motives guiding people to act or behave in a certain way. They are believed to be more complex, more basic, and more enduring than attitudes, opinions, and preferences" (Halman 2001: 1).

Professor Jack Denfeld Wood makes a further distinction between values and beliefs. Not all researchers in this field follow this example. "By belief I mean a seemingly rational conviction about what is 'true' and what is 'false'. Belief is 'existential' in the sense that it concerns what is presumed to 'exist' as fact. A belief need not include a valuation. By value I mean something more akin to a felt emotional conviction about what is 'good' and what is 'bad'. True and false are not equivalent to good and bad. A value implies comparative worth. A belief can be more or less neutral but a value cannot. A value is always relative" (Wood 1997: 616-617).

Norms are the application of values in day-to-day reality, the actual expression of values.

Research of values is difficult. Values are of course no concrete things but a deduction or interpretation of the behaviour of people; a construct. Furthermore, values are mostly unconsciously present in our thinking. A solution lies in carefully drafted questionnaires, asking all the time what people consider important, often on the basis of a series of alternatives.

A good example of values research may be found in the European Values Study (EVS) and the World Values Survey (WVS). Tilburg University started the former in the late seventies, a comparative research project to delineate value patterns in a number of countries. The original focus areas were religion and morality, work, family and politics. After surveys in 1980 and 1990 these efforts were joined by a similar US research project in other countries. The outcomes of the surveys in 2000 by the two groups were merged in one database and are accessible through internet (www.worldvaluessurvey.org).

\section{Comparing National Cultures}

If national cultures are a mix of many thousands smaller cultures, one may wonder why to study cultures at this level at all. The short answer is given by Thomas and Inkson (2004: 27): "National cultures are particularly important in international business because of the concept of national sovereignty and the need to conduct business affairs within national, legal, and political frameworks".

In the sixties internationalising business discovered the importance of culture in implementing contracts, directing personnel, marketing and advertising and so on. Available studies did not fit well with the needs of business. International business required a practical model, resulting in clear guidelines for what to do. The research in the late sixties by Hofstede (1999) responded to this need. Hofstede applied a thorough statistical analysis on the response to questionnaire
HANDLING CULTURE

Pieter J.M. van Nispen tot Pannerden 
Pieter J.M. van Nispen tot Pannerden and concluded that the answers to the questions could be divided in clusters. Later researchers as Trompenaars (1997) and Solomon and Schell (2009) also conducted comparative studies for business. Such an approach gives an overall picture of national cultures, particularly in patterns of thinking. However, these perceptions do not contain specific elements, such as traditions and folklore. In this sense these approaches are a necessary but insufficient ingredient.

The research by Hofstede results in easy to use key figures per country. However, this cannot be stressed enough, these figures are not more than aggregates of individual perceptions and an individual person never fits completely his or her national average. Furthermore, a national culture consists of many subcultures, which may vary considerably from the overall picture. Next to this rather general word of caution, other researchers have expressed methodological criticism, requiring even more caution in the use of this research. However, we should keep in mind that this research was an innovation, the first large-scale sociological comparative research of national cultures and is still widely used.

Hofstede (1999) defines the original four dimensions as follows:

a) Power Distance: the extent to which the less powerful members of society accept that power is distributed unequally,

b) Masculinity versus femininity:

- Masculinity: the dominant values in society are achievement and success,

- Femininity: the dominant values in society are caring for others and quality of life,

c) Individualism versus collectivism:

- Individualism: people look after themselves and their immediate family only,

- Collectivism: people belong to in-groups (families, clans or organizations) who look after them in exchange for loyalty,

d) Uncertainty Avoidance: the extent to which people feel threatened by uncertainty and ambiguity and try to avoid these situations.

For each of these four dimensions Hofstede developed lists of characteristics for scoring either high or low on a given dimension. He also 'translated' the four dimensions to business environments.

Trompenaars (1997) perceives culture as finding answers to the key dilemmas of life. People find their own positions somewhere between the two extreme positions. Trompenaars does not give figures per country but he does show how populations in different countries answer to questions, related to his seven dilemmas. These seven dilemmas are divided in three: relations between people, attitudes to time and attitudes to environment. The first one (relations between people) is further split in five:

1) relations between people: 
a) universalism versus particularism or a focus on rules versus an emphasis on circumstances,

b) individualism versus communitarianism: what we want as an individual versus the interest of the group we belong to,

c) neutral versus affective; degree of showing emotions,

d) specific versus diffuse: degree to which we engage others in specific areas of life and single levels of personality, or diffusely in multiple areas of our lives and at several levels of personality at the same time:

- achievement versus ascription: according status, either on the basis of their achievements or on the basis of age, class, gender, education et cetera,

2) attitudes to time:

a) sequential (line of events) versus synchronic (cyclical and repetitive),

b) we think about past, present and future with relative time horizons,

3) attitudes to environment:

a) inner directed: societies believe that they can and should control nature by imposing their will upon it,

b) outer directed: societies believe that man is part of nature and must go along with its laws, directions and forces.

The American consultants Solomon and Schell (2009) do not give information on their research methods but make the questionnaire available and the positions of 50 countries on their seven keys. Talking to people from these countries and using it in multicultural classrooms their results appear to be overall supported:

- Egalitarian/Hierarchical,

- Group Focus,

- Relationships,

- Communication Styles,

- Time Orientation,

- Change Tolerance,

- Motivation/Work-Life Balance,

- National and organisational cultures.

\section{Communication}

An important aspect of the cultural competence is communication, often called intercultural communication (inter $\sim$ stresses differences, cross $\sim$ the commonalities and trans a higher level which reconciles both differences and commonalities). Communication requires a separate discussion but three remarks may be made. The first is a thesis: whatever model of communication one may use, each aspect of that model is being influenced by culture. No communication without culture and although culture requires communication, it may exist without communication (e.g. architecture). 
HANDLING

CULTURE

Pieter J.M. van Nispen tot Pannerden
Secondly one may consider the findings of neuro-linguistic programming, in particular those by the psychologist Albert Mehrabian. In a face-to-face communication only $7 \%$ of that communication consists of the content of words, $38 \%$ the tone of voice and $55 \%$ of body language. Again, culture plays a role on all three, whether these figures are accurate in any culture or not. Speaking another language, decreasing the already meagre $7 \%$. This may be compensated by the other two elements but they are also influenced by culture and generally speaking people are even less aware of these effects of culture. A similar tone of voice may have quite a different connotation from the one culture / language to the other. In the same vein gestures may have quite different meanings; an OK sign may turn into an insult. For these reasons getting a message across the borders of culture and language requires some additional efforts (more redundancy for example by passing the message on in two different formats, checking what the other party has understood) while at the same time quite some pitfalls need to be avoided.

Body language is often neglected and its importance need to be stressed time and again; see for instance The Definitive Book of Body Language by Barbara and Allen Pease (2004). Part of body language is biological and part of it is learned (cultural body language). Important is always to see body language in the context of the overall communication in order to come to a proper understanding.

Body language falls into the following categories (see also Guirdham 2005):

- Kinesics: body movements,

- Proxemics: use of space,

- Prosodic characteristics: tone, volume, laughing, sniff, sigh,

- Appearance: physical characteristics, clothing, make-up,

- Haptics: touching the other,

- Artefacts: objects of the person,

- Other non-verbal communicative indications: the situation at hand (interior) and do-language (cooking food).

Long lists indicate all kinds of body language, ranging from things human beings cannot control to deliberate gestures. Once again, you may learn about gestures in other countries but you most probably will also make mistakes by using automatically one gesture or another which you better did not make.

\section{Preparing for cultural differences}

A rather comprehensive approach for the preparation of cultural differences was developed through lecturing and experience and may be demonstrated by the Wegoman case. Wegoman is an imaginary company, providing management training (see box 1). Important is to note the cultural difference between a production company and a service providing company. From an economic point of view the transaction with a production company takes place after the work is done (the product may be tested etc.) while the services still need to be rendered 
after the contract has been concluded. It implies that trust plays a much more important role in services than in production and hence, culture because the level of trust is much determined by culture(s).
HANDLING CULTURE

Pieter J.M. van Nispen tot Pannerden

\section{Box 1: Wegoman case}

The case concerns a Dutch service providing company which intends to provide its services in another country (see below). Its name is Wegoman and has 52 employees. The core business is management training. Courses may be contracted or followed by subscribing to the open enrolment programme. They are provided at the Wegoman offices in Alkmaar, Zeist or Weert or in-house at the customer's location. Wegoman's main office is at Zeist, the two other locations are rented locations for training purposes only.

The 52 employees are divided as follows:

- 1 director and senior trainer,

- 41 trainers with specialisations in HRM, finance, logistics, change management, marketing and sales, procurement, communication, production, IT and leadership, some of them in principle divided over the three locations,

- 10 support and back office: one office manager, one financial officer, one IT support specialist, three administrative staff members, one copier (assembling training folders), one marketing specialist (including acquisition support), one driver (part-time), one lay-out specialist,

- Personnel administration, maintenance and cleaning is provided by other parties under contract.

The company exists for 9 years. The variety of the trainers expertise has shown to be an advantage during economic downturns because Wegoman could respond to needs still existing in those periods. However, it also faced some difficulties of its own due to the quick growth and consequent less favourable decisions. The idea that each trainer would keep his or her own network and would be able to acquire a 150 billable days proved to be an optimistic assumption. Furthermore, the organisational culture needed some attention, developing from the ideas of the first director into something widely shared by all staff members.

Wegoman still has good opportunities in the Dutch market. In a way, marketing training is of all times, because new employees enter new jobs all the time. The overall training concept has been well developed and is shared by all trainers. The question is whether this concept may also be tried in other countries where the need for training is still very large. Such an approach might give an additional impetus to the organisation. 

CULTURE

Pieter J.M. van Nispen tot Pannerden
HANDLING

After some discussions between the director of Wegoman and the trainers, the company has decided to look for opportunities within a specific country (your choice, see below). You know already that Wegoman has decided to send one of its trainers for a three year period to that country. Next to the usual entrepreneurial spirit, hunting for opportunities, this is considered as a major investment. For this reason Wegoman looks for opportunities to turn the stay of one of its employees abroad into a success by creating the best possible conditions.

Students work on the Wegoman case in four steps. Prior to these four questions, they have to choose a country in which Wegoman might open a daughter company. The list of available countries is the overlap from the World Values Survey and Solomon \& Schell (see box 2).

\begin{tabular}{|l|l|l|l|}
\hline \multicolumn{5}{|c|}{ Box 2: available countries } \\
\hline Argentina & Finland & Mexico & Spain \\
\hline Australia & France & New Zealand & Sweden \\
\hline Austria & Germany & Norway & Switzerland \\
\hline Belgium & Greece & Philippines & Turkey \\
\hline Brazil & India & Poland & Ukraine \\
\hline Canada & Indonesia & Portugal & United \\
\hline Czech & Ireland & Romania & Kingdom \\
\hline Republic & Israel & Russia & United States \\
\hline Denmark & Italy & Singapore & Vietnam \\
\hline Egypt & Japan & South Korea & \\
\hline
\end{tabular}

The first question is: give an overview of the cultural differences in general between the Netherlands and the country selected, using internet. The focus is not on a specific theory on cultural differences but rather on general aspects, including language, religion, history, body language, ways of doing things and patterns of thinking. Time and time again students come up with a sometimes amazing amount of information in only a few hours of surfing, such as traditions, customs, national days or celebrations, gestures, clothing styles, specific use of business cards and aspects of communication.

The background to this question is that the theories for comparing national cultures do not mention the more specific aspects such as folklore and tradition and bypass the richness or variety within the national culture studied. The few hours of surfing however, hardly provide historical knowledge and its effects on national mentality. According to some authors the historical background may provide up to half of the understanding of another culture. An example of such a study is the work by Han van der Horst: Under a low Sky (2001). He wrote 
effects of history. This historical aspect needs to be included in real life, in the actual situation of preparing for doing business on some scale with a partner in another country of even opening offices over there.

After establishing a general idea of 'their' country, students are asked to apply the theory of Solomon and Schell. To answer this second question students receive the scores of 50 countries on the seven keys After establishing the scores for the Netherlands and the target country students need to indicate the meaning of the differences they found. As Solomon and Schell say: small differences may have rather big consequences in day-to-day life. Furthermore, they need to compare their outcomes with the first question.

If a company is interested in a country, which is not included in the research mentioned, it may apply the questionnaire itself. Solomon and Schell give full access to the questions, the processing and the results. Establishing a representative sample for a country is of course too demanding for a company but filling out the form and discussing the results with some local contacts may already give a strong impression of where differences might be found.

The third step is to compare countries by outlining the differences in value patterns. These may be found on the website of the World Values Survey (www. worldvaluessurvey.org) - online data analysis, selection of countries, going through the questions and spotting the differences. This website does not only contains lots of information but also offers many ways of presenting information and to copy it to an Excel file.

Finally students are asked to take all information together and to provide an overall view in the form of an advice to Wegoman's management. After outlining the major cultural differences students need to indicate what the consequences are for the business of Wegoman. Points of attention include business activities (aspects of management, aspects of management training, negotiation styles with customers), the daughter company (internal management, organisational structure, other aspects) and communication. Key is however, that students that management and training styles are different across cultures. Hence, the content of the training and the way of giving the training need to be adapted. The question then becomes whether a company like Wegoman may still provide its own services according to its own concept or has to develop a new concept, more or less starting from scratch.

Dealing with cultural differences in a more general way may be depicted as a bridge (Figure 4) between your own culture and the culture of the other party you are dealing with. Such a bridge is founded on respect for the other as a fundamental condition, based on the equality of people. This approach focuses on practical applications for business, rather than a primary focus of scientific research. 
Pieter J.M. van Nispen tot Pannerden

Figure 4. Dealing with cultural differences common interests

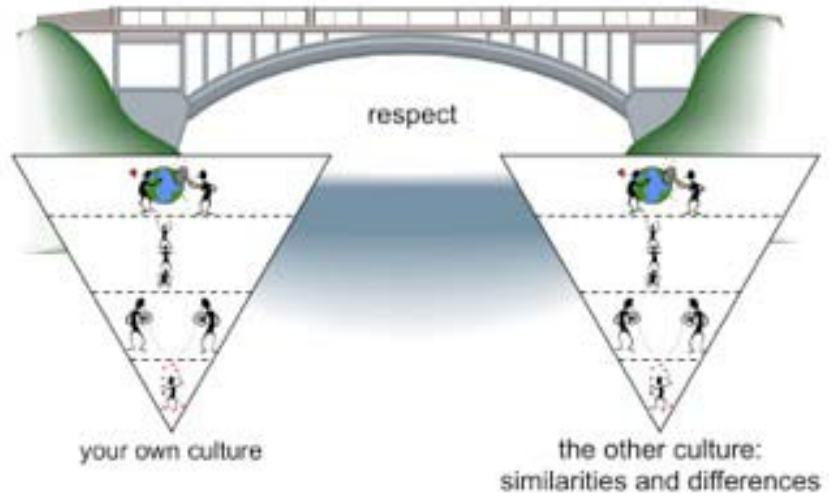

Knowing your one culture implies knowing you yourself as well as the culture of the country you are coming from, including the stereotypes regarding your own country. Learning about the culture of the other may start with the stereotypes, move through an understanding of the other culture and end with an understanding of the other as an individual person.

A key aspect of respect is that you reserve your judgement of the situation. To start with, not all differences are cultural differences. In evaluating the situation at hand you should see the distinction between recognising things as different and finding it 'odd' or 'strange'.

\section{Conclusion}

Culture is a concept many people have an idea of but which proves hard to grasp if you try to define it. Many disciplines have tried to do so for decades and the result is a kaleidoscope of definitions, concepts, conditions, criteria et cetera. This result presents a problem for those who have to deal with culture and cultural differences. A large group of those people consists of businessmen and women who increasingly operate in an international environment.

An expression in Dutch says 'if it cannot as it should, it should as it can'. In the context of this article the first part indicates that research does not provide sufficient answers for business on how to deal with cultural differences and the second part of the expression that nevertheless practical solutions are possible. These solutions include what research has provided up till now or at least some selected parts of research, applicable to the situation.

This practical approach consists of the cultural competence, an integral combination of (the available) knowledge on culture, skills (in particular the adaptation of behaviour) and attitude (in particular respect). This article stressed the knowledge part and emphasised the following points: 
- Culture may be understood by six elements (values and beliefs; thinking and feeling; behaviour; group; time; place) and four levels, depending the size of groups (national culture, organisational culture, team culture, individual culture);

- Individual culture is the unique combination of all cultural influences ever exercised on an individual person (the hundreds of groups s/he has ever been a member of) and is also the starting point for dealing with cultural differences;

- Culture plays its role in the background and more often than not people are not even aware of it (unconsciously);

- The most 'hidden' part of culture is the set of our values and norms. However, they may be studied through questionnaires and other methods of sociological and psychological research;

- The cultures of states are common denominators with strong effects on political, economic, legal and similar national frameworks but with limited use for understanding an individual person.

In short, culture may be hard to grasp and have strong effects but whatever it is, it does not need to elude us or to escape from our control. On the contrary we can deal with it and be better of as a result of it.

\section{References}

Adler, N. (1996), International Dimensions of Organizational Behavior, South Western College Publishing.

Barker, J.A. (1996), Paradigma's, mentale modellen voor de toekomst, Scriptum Management, Schiedam; Dutch translation of Paradigms; the Business of Discovering the Future.

Guirdham, M. (2005), Communicating across cultures at work, Palgrave Macmillan.

Halman, L. (2001), The European Values Study: A Third Wave. Source book of the 1999/2000 European Values Study Surveys, EVS, WORC, Tilburg University.

Hoffman, E.M. (1999), The TOPOI-model, A pluralistic systems-theoretical approach of intercultural communication ( $\mathrm{PhD}$ thesis in Dutch with a summary in English).

Hofstede, G. (1999), Allemaal andersdenkenden, omgaan met cultuurverschillen, Uitgeverij Contact; Dutch translation of Cultures and Organizations, Software of the Mind.

Horst, H. van der (2001), Lage hemel, Scriptum, Schiedam.

Hulleman, W. and Marijs, A.J. (2003), Internationale economische ontwikkelingen en bedrijfsomgeving, Wolters-Noordhoff, Groningen / Houten.

Georgas, J. et al. (2006), Families across Cultures, A 30-Nation Psychological Study, Cambridge University Press, Cambridge.

Kooijmans, P.H. et al. (2008), Internationaal publiekrecht in vogelvlucht, Kluwer, Deventer.

Kottak, C.P. (2000), Anthropology, The Exploration of Human Diversity, McGraw Hill (eighth edition). 
HANDLING CULTURE

Pieter J.M. van Nispen tot Pannerden
Mole, J. (1997), Zo doen we dat! over het omgaan en samenwerken met Europeanen, Academic Service; Dutch translation of Mind your Manners.

Nispen, P. van (2011), Cultural Competence, an app for the iPad.

Oudenhoven, J.P. van (2002), cross-culturele psychologie, Uitgeverij Coutinho, Bussum.

Pease, A. en Pease, B. (2004), The Definitive Book of Body Language, Orion.

Smith, P.B and Bond, M.H. (1998), Social Psychology Across Cultures, Pearson Prentice Hall, London.

Solomon, Charlene M. and Schell, Michael S. (2009), Managing across Cultures, The Seven Keys to Doing Business with a Global Mindset, McGraw Hill.

Thomas, D.C.and Inkson, K. (2004), Cultural Intelligence, People Skills for Global Business, Berrett-Koehler Publishers Inc.

Trompenaars, F., \& Hampden-Turner, C. (1997), Riding the Waves of Culture, understanding cultural Diversity in Business, Nicholas Brealey Publishing.

Valsiner, J. (2000), Culture and Human Development, SAGE Publications, London.

Wood, J. D. (1997b), The Nature of Ideology, in Mastering Management, Financial Times Pitman Publishing. 